\title{
Effect of the Continuum Removal in Predicting Soil Organic Carbon with Near Infrared Spectroscopy (NIRS) in the Senegal Sahelian Soils
}

\author{
Macoumba Loum¹, Mateugue Diack¹, Ndeye Yacine Badiane Ndour ${ }^{2}$, Dominique Masse ${ }^{3}$ \\ ${ }^{1}$ UFR de Sciences Agronomiques, de l'Aquaculture et de Technologies Alimentaires, Université Gaston Berger, Saint-Louis, Sénégal \\ ${ }^{2}$ Institut Sénégalais de Recherches Agricoles, Laboratoire LNRPV, Dakar, Sénégal \\ ${ }^{3}$ IESOL Laboratoire Mixte International Ecologique des Sols Cultivés en Afrique de l'Ouest, Centre ISRA/IRD, Dakar, Sénégal \\ Email: macoumbaloum@yahoo.fr
}

How to cite this paper: Loum, M., Diack, M., Ndour, N.Y.B. and Masse, D. (2016) Effect of the Continuum Removal in Predicting Soil Organic Carbon with Near Infrared Spectroscopy (NIRS) in the Senegal Sahelian Soils. Open Journal of Soil Science, 6, 135-148.

http://dx.doi.org/10.4236/ojss.2016.69014

Received: August 19, 2016

Accepted: September 20, 2016

Published: September 23, 2016

Copyright $(9) 2016$ by authors and Scientific Research Publishing Inc. This work is licensed under the Creative Commons Attribution International License (CC BY 4.0).

http://creativecommons.org/licenses/by/4.0/

\begin{abstract}
Spectroscopy plays a major role in the access of the analytical parameters of the soil. It tends to substitute the conventional laboratory analysis because hyperspectral data were least expensive and easier to obtain. The objective of this study was to evaluate the effect of the continuum removal (CR) in the validation of the accurate prediction model of the soil properties with Vis-NIR spectroscopy data. Few studies using Vis-NIR reflectance spectroscopy have well focused the calculation of the CR method; its effect in the calibration of the accurate models was also not well emphasized. In this study, we used the remote sensing software ENVI 4.7 to compute the CR function where the value of the continuum for each sample and for each spectral wavelength was obtained by dividing the reflectance values of the full spectrum (FS) with those of the continuum curve (CC). The partial least square regression (PLSR) model was applied in the spectral data from the soil of the Senegal Sahelian region. It was calibrated with both data from the full spectrum (FS) and those obtained after the application of the continuum removal. With the application of the CR, ultraviolet wavelengths $(350-429 \mathrm{~nm})$ and those of near infrared $(2491-2500 \mathrm{~nm})$ were removed from the explanatory variables of PLSR model. With the FS, all wavelengths between 350 and $2500 \mathrm{~nm}$ were taken into account in predicting soil properties. Our findings show a positive effect of the application of CR in the estimation of soil organic carbon. In calibration, the $\mathrm{R} 2$ increased up to $10 \%$ with the continuum removal in the model of 12 components $(\mathrm{CP})$. In terms of validation, it's the 15-component model which is the most accurate with the same range in calibration between the FS and the CR. The lowest RMSE ranged from 0.04 with the FS to 0.03 with the application of the CR in calibration and validation. These results show that the interest of this study as soil organic carbon is recognized as a key indicator of fertility of the soil
\end{abstract}


in Sahelian-African regions. For future studies, it's important to apply the model of neural networks to better evaluate the effect of continuum removal in predicting soil properties from the spectral data and other methods of preprocessing like the multiplicative scatter correction (msc).

\section{Keywords}

NIRS, Soil Proprieties, Continuum Removal, PLSR Model, Senegal River Delta

\section{Introduction}

The validation of prediction models from spectral data can contribute to better develop precision agriculture with ability of the spectroscopy to provide more efficiently analytical parameters of the soil on large datasets [1]. Conventional laboratory analyses of soil properties are expensive [2]. The processing time requires also intensive labour to generate the necessary data [3]. However, spatial characterization of soil variability at a fine scale is often necessary for a sustainable management of the soil cover [4]. Spatialization of soil properties is also an important factor for the monitoring of soil moisture, soil fertility and soil acidification [5]. This needs to have detailed information on soils with alternative methods, at lower cost, which is a real challenge in the developing countries where the availability of analytical equipment of soils remains widely in sufficient. Furthermore, organic matter is recognized as good indicators of the quality of the soil in the Sahelian agrosystem in Senegal [6] [7]. In this fact, calibration of prediction models on these agro-pedological variables becomes an issue of sustainable development knowing that agricultural production plays a major role in food security and in performing economies in sub-Saharan African countries [8]. Also, with the global warming, the promotion of management strategies which allow the storage of carbon in the soil and reduce emissions of carbon dioxide in the atmosphere is required [9]. In the international context, mathematical and statistical methods of prediction are increasingly tested in the soil properties analysis protocols in relation to spectroscopy data [10]-[15]. The possibility offered by spectroscopy to generate reflectance and luminance spectra in different wavelengths $250-400 \mathrm{~nm}$ (ultraviolet; UV), $400-700 \mathrm{~nm}$ (visible; VIS), 700 - $2500 \mathrm{~nm}$ (near infrared; NIR), 2500 - 25,000 nm (med infrared, MIR) allows an extraction of useful information about soil components at lower cost [16] [17]. Hence, the interest of pursuing research in spectroscopy was to implement more accurate and reproducible model estimation of soil properties. For the exploration of these spectral data, pre-processing functions were carried out to determine the most relevant spectral wavelengths for estimating soil properties [18]. The applications of statistical model associated with other processing functions have given good results in the analysis of soil properties through spectroscopy [2] [5]. The continuum removal (CR) is one of the examples of pre-treatments which allowsto isolate particular absorption features in diffuse reflectance spectra on the soils [19]. After isolation, these 
absorption wavelengths were removed in the explanatory variables of the model in order to minimize errors prediction. The CR was calibrated with the PLSR (Partial Least Square Regression) model to evaluate the level of accuracy in predicting soil organic carbon from the spectral data. The application modalities of continuum removal raised some scientific questions. First of all, few studies have demonstrated the implementation of CR calculation method in spectroscopy of soil data [1]. Secondly, its real effects in the estimation of physical, chemical and biological properties of soils are not sufficiently focused. The objective of this study was then to better understand the function of the continuum removal (CR) and to evaluate this effect in terms of accuracy level of the prediction for the soil organic carbon from spectral soil data.

\section{Material and Method}

\subsection{Study Area}

The study area is located in the lower delta of the Senegal River. It corresponds to the30-ha agricultural farm of the University of Saint Louis, where a tributary of the Senegal River (the Djeuss) allows development of farming activities. The climate is a sub-Canarian to Sahelian with a short rainy season between July to October (Table 1) and a dry season that lasts from November to June. The natural vegetation cover is a shrub steppe comprising mainly Acacia raddiana, Balanites aegyptiaca, Prosopis juliflora and Euphorbia balsamifera. The study area is an experimental site of market garden, horticultural and rainfed crops. However, the need to promote precision agriculture required to correct the lack of information on the spatial variability of the physical and chemical soil properties. So, we have performed a stratified sampling point of the soil following a regular grid of $30 \mathrm{~m}$ by using Landsat imagery and Google Earth. A total of 216 sampling points, meaning 3 - 4 points for each plot were selected. The geographical coordinates of each point are located by GPS survey and referenced in a geographic information system (Figure 1). Soil profiles were sampled with auger in the following depths: $0-10 \mathrm{~cm} ; 10-20 \mathrm{~cm} ; 20-40 \mathrm{~cm} ; 40-60 \mathrm{~cm}$ and $60-80 \mathrm{~cm}$. For each depth, a composite sample is created by mixing 3 primary samples; with 1080 soil samples collected in the study area, 432 were analysed for the biochemical and chemical

Table 1. Monthly evolution of the rainfall over the last five years (2010-2015).

\begin{tabular}{cccccccc}
\hline Year & June & July & August & September & October & November & December \\
\hline 2010 & 28.0 & 70.0 & 66.0 & 320.0 & 109.0 & 0.0 & 0.0 \\
2011 & 0.0 & 49.0 & 108.0 & 116.0 & 4.0 & 0.0 & 0.0 \\
2012 & 0.0 & 74.0 & 106.0 & 190.0 & 8.0 & 0.0 & 2.0 \\
2013 & 0.0 & 60.0 & 151.0 & 152.0 & 4.0 & 1.0 & 8.0 \\
2014 & 0.0 & 2.0 & 69.0 & 26.0 & 16.0 & 0.0 & 0.0 \\
2015 & 0.0 & 7.0 & 137.5 & 83.0 & 13.0 & 0.0 & 0.0 \\
\hline
\end{tabular}

Source: Agence Nationale de l'Aviation Civile et de la Météorologie (ANACIM, 2015). 


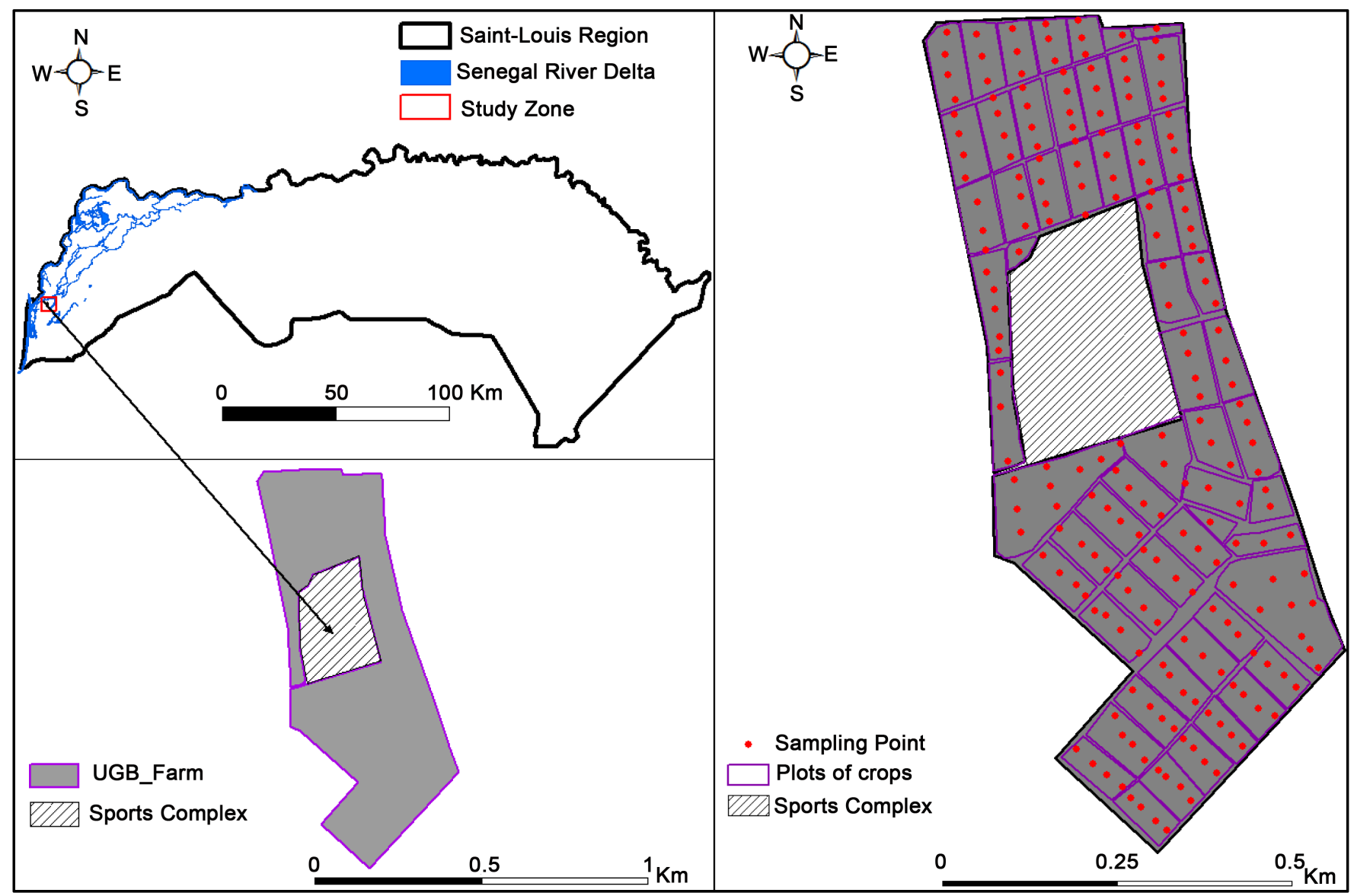

Figure 1. Location of the study area and sampling point of soil properties.

properties in the Africa Rice laboratory. The validation of a prediction model from the Vis-NIR spectroscopy data will be able to estimate the biochemical and chemical properties of the soil on the 648 remaining samples.

\subsection{Spectral Data}

The reflectance of soil samples was measured with the spectroradiometer of the ASD Company (Analytical Spectral Devices, CO) at the Institute of Research for Development (IRD, Center of Dakar). Samplesof about $10 \mathrm{mg}$ amount of soil were put into Petri dishes. Soil spectra were detected over the wavelength ranging from $350 \mathrm{~nm}$ (UV) to2500 $\mathrm{nm}$ (NIR). The spectral reflectance was first performed with measurements at the absolute reflectance (baseline) with a white Spectralon panel. For the soil samples, measurements were repeated three times and the logarithmic values of reflectance were stored in auto save document (.asd file) and were converted to ASCII files with InDiCo Pro software. With Excel software, the matrix of input variables for the model prediction was built from the average of 3 measurements for each soil sample.

\subsection{The Continuum Removal}

The continuum removal (CR) was a pre-treatment function used in spectroscopy to 
improve the estimation of soil properties [1]. It allowed to isolate a particular absorption feature for analysis of a spectrum and represented the absorption due to a different process in a specific mineral or possibly absorption from a different mineral in a multimineralic surface [20] [21]. We have computed the continuum removal (Equation (1)) and the continuum curve (Equation (2)) in the remote sensing software of Envi ${ }^{\circledR} 4.7$. The matrix of the full spectrum (FS) was before transformed in txt format. The spectral library builder optionof $\mathrm{Envi}^{\circledR} 4.7$ allowed to calculate the reflectance value of the continuum removal (CR) from the reflectance value of the full spectrum (FS). Afterwards, the transformation of these two matrixes (FS and CR) into spectral band allowed to compute the reflectance value of the continuum curve with the BandMath function of Envi ${ }^{\oplus} 4.7$ software.

$$
\begin{aligned}
& \mathrm{CR}=\mathrm{FS} / \mathrm{CC} \\
& \mathrm{CC}=\mathrm{FS} / \mathrm{CR}
\end{aligned}
$$

where CR = Continuum Removal; FS: Full Spectrum; CC: Continuum Curve.

\subsection{The PLSR Model}

The partial least square regression (PLSR) was used to estimate soil organic carbon. The comparison of different data mining algorithms for prediction of soil properties from the spectral reflectance data showed regression performance via Support Vector Machine $(0.92 \%$, RMSE) followed respectively by the partial least square regression $(0.96 \%$, RMSE) and the Stochastic gradient boosting (1.02\%, RMSE) [16]. One of the advantages of PLSR compared to other chemometric methods like principal component analysis is the possibility to interpret the first few latent variables (LV), because they show the correlations between the property values and the spectral features [22]. The PLSR enables to understand and describe the often complex relationship between two types of variables X and Y [23]; X often composed of several variables, is called explanatory variables and Y represents the response variable [24]. The PLSR model was based on a linear relationship between soil properties and spectral data (Equation (3)) that were characterized by the complexity and the richness of information they contain [10]. Soil samples were taken from the lower delta of the Senegal River. The PLSR (partial least square regression) was performed in R 3.1.2 software [25] to estimate the soil organic carbon.

With the PLS model, the database was divided into two separate sets for calibration and validation. A recursive split with the principal component analysis (PCA) method allows us to select the 186 soil samples and which was tested the PLSR model. The PCA applied to the full spectrum was also used to select the $2 / 3$ of the dataset (124 soil samples) used in calibration; the $1 / 3$ remaining (62 soil samples) was used to validation (Figure 2).

$$
Y=\sum_{i}^{P} b_{i} X_{i}+\varepsilon_{0}
$$

where $Y=$ the estimated value; $b_{i}$ : the coefficients of the model to the wavelength $i ; X_{i}$ : the reflectance at the wavelength $i ; \varepsilon_{0}$ : the residual error; $P$ : value of reflectance spectra. 


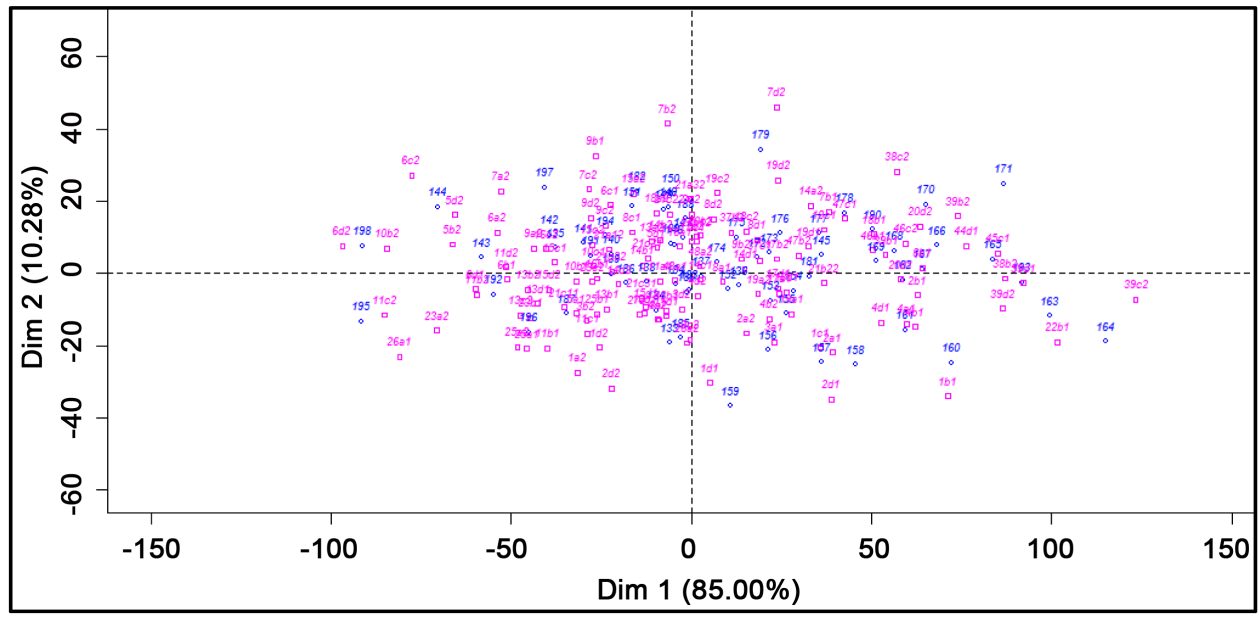

Figure 2. The spectra validation in supplementary individual in the factorial plane of PCA.

The validation data is put on supplementary individuals in the factorial plane of the PCA (Figure 2). We have taken into account the variability of the individuals knowing that the result of PCA with addition to the first and second axes were superior to $80 \%$.

The PLS model transforms the explanatory variables into latent variables (called components) through a linear combination of the least correlated variables. The leave one out cross-validation method allows to choose the optimal number of components whose lowest RMSE (root mean square error) was selected [26]. The R2 (determination coefficient) is another index that measures the performance of the PLSR model. It refers to the part of inertia explained by the model on the total variability. With the CR, the ultraviolet $(350-429 \mathrm{~nm})$ and the near infrared (2289 to $2500 \mathrm{~nm}$ ) wavelengths which values of reflectance were equal to1were removed from the spectrum in the prediction model. The model was turned on both with data of the full spectrum $(350 \mathrm{~nm}$ to $2500 \mathrm{~nm}$ ) and that those of the continuum removal (430 - $2490 \mathrm{~nm})$.

\subsection{The Analytical Data}

The PLSR model was performed on 186 soil samples selected according to their variability on the factorial plane of the PCA. The box plots of the soil organic carbon computed with $R 3.1 .2$ software shows a range between $0.07 \%$ to $0.39 \%$; the average organic carbon content was around to $0.20 \%$ (Figure 3 ).

\section{Results}

Following the application of the continuum function, the wavelengths with reflectance value equal to 1 were removed from the matrix of the explanatory variable. The absorption peaks of the organic carbon (OC) were then better highlighted with the evolution of the regression coefficients of the continuum removal in comparison with the full spectrum (Figure 4 and Figure 5). Furthermore, the comparative analysis of reflectance values of CR in three soil samples showed higher peak reflectance on the sample that had a high level of soil carbon. The $2 \mathrm{c}-1$ sample with a carbon content of $0.38 \%$ 


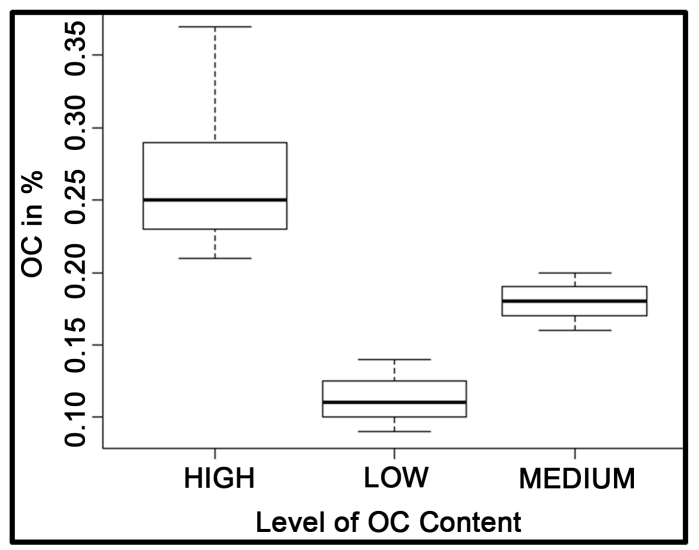

Figure 3. The box plots of the range of the soil organic carbon content of the data set.

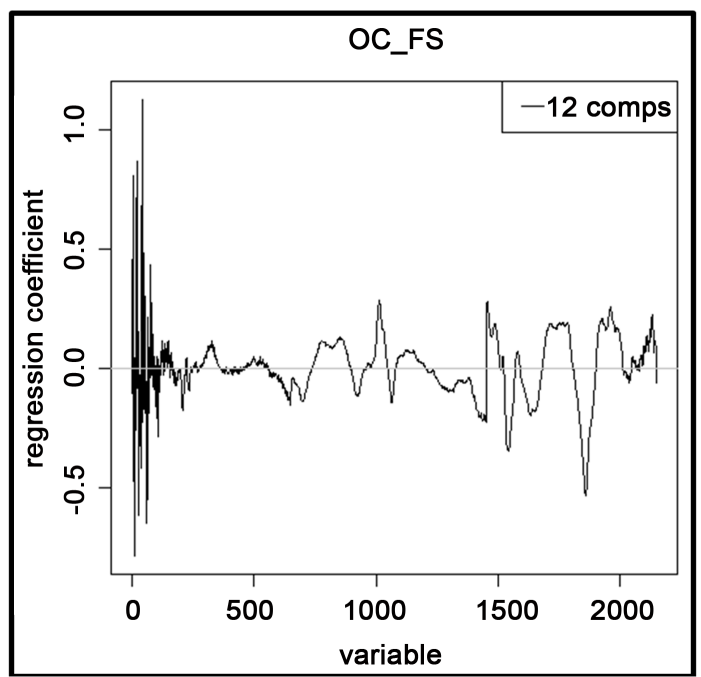

Figure 4. Changes in regression coefficients with the Full Spectrum (FS).

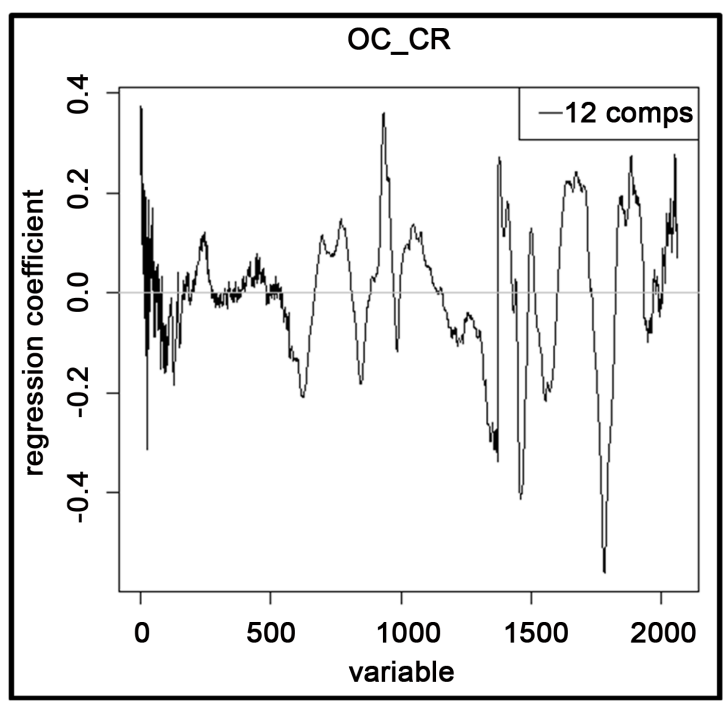

Figure 5. Changes in regression coefficients with the Continuum Removal (CR). 
showed absorption peaks of 0.6 in the $\mathrm{CR}$ whereas the sample $17 \mathrm{c}-2$ with lower carbon contents $(0.09 \%)$ showed absorption peaks of about 0.4 (Figure 6).

The average error rate becomes lower with the CR both in calibration and validation results of carbon estimation. With the model calibration of 12components (Figure 7(a)), the RMSE decreased from 0.04 in full spectrum (FS) to 0.03 after the continuum removed (CR). In validation (Figure 7(b)), it's the model of 15 components which provided more accurate result with RMSE ranging from 0.04 in the full spectra to 0.03 in the CR. At the same time, the coefficient of determination (R2) increased from 0.6 (FS) to 0.7 (CR) in calibration at the model of 12 components (Figure 8(a)). For the validation, the R2 ranged from 0.6 (FS) to 0.7 (CR) at the model of 15 components (Figure $8(\mathrm{~b})$ ). The average organic carbon content for the observed data is $0.21 \%$. The predicted one with the continuum removal is also $0.21 \%$. With the full spectrum (FS), predicted data equal $0.20 \%$ (Table 2 ).

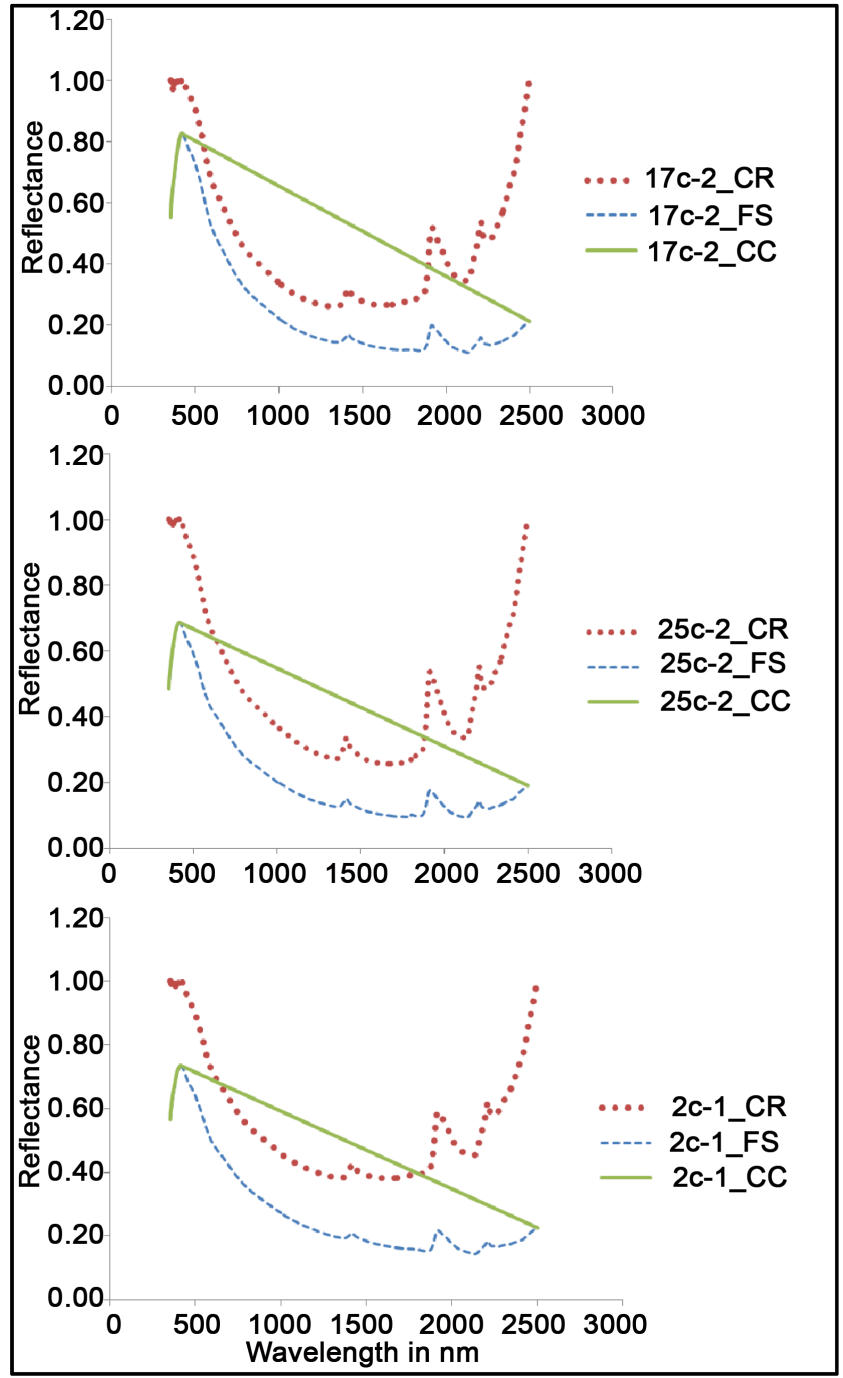

Figure 6. Comparison between changes in reflectance values of the full spectrum (FS) continuum removal (CR) and continuum curve (CC) of three soil samples. 
Table 2. Observed and Predicted organic carbon content using the PLS model with the full spectrum (FS) and the continuum removal (CR) from the $1 / 3$ data set of validation.

\begin{tabular}{|c|c|c|c|c|c|c|c|}
\hline Samples & OC_Obs & $\begin{array}{l}\text { OC_Pred_FS } \\
(12 \mathrm{Cp})\end{array}$ & $\begin{array}{c}\text { OC_Pred_CR } \\
(15 \mathrm{Cp})\end{array}$ & Samples & OC_Obs & $\begin{array}{c}\text { OC_Pred_FS } \\
(12 \mathrm{Cp})\end{array}$ & $\begin{array}{c}\text { OC_Pred_CR } \\
(15 \mathrm{Cp})\end{array}$ \\
\hline 125 & 0.13 & 0.14 & 0.12 & 156 & 0.17 & 0.19 & 0.18 \\
\hline 126 & 0.25 & 0.12 & 0.18 & 157 & 0.25 & 0.26 & 0.26 \\
\hline 127 & 0.26 & 0.25 & 0.26 & 158 & 0.28 & 0.25 & 0.24 \\
\hline 128 & 0.14 & 0.13 & 0.13 & 159 & 0.17 & 0.14 & 0.13 \\
\hline 129 & 0.24 & 0.2 & 0.21 & 160 & 0.20 & 0.21 & 0.19 \\
\hline 130 & 0.21 & 0.16 & 0.17 & 161 & 0.18 & 0.14 & 0.23 \\
\hline 131 & 0.18 & 0.22 & 0.19 & 162 & 0.26 & 0.23 & 0.25 \\
\hline 132 & 0.26 & 0.24 & 0.26 & 163 & 0.32 & 0.27 & 0.26 \\
\hline 133 & 0.34 & 0.33 & 0.32 & 164 & 0.20 & 0.18 & 0.16 \\
\hline 134 & 0.17 & 0.17 & 0.18 & 165 & 0.23 & 0.22 & 0.22 \\
\hline 135 & 0.16 & 0.22 & 0.21 & 166 & 0.16 & 0.21 & 0.22 \\
\hline 136 & 0.17 & 0.16 & 0.15 & 167 & 0.39 & 0.38 & 0.40 \\
\hline 137 & 0.13 & 0.1 & 0.12 & 168 & 0.27 & 0.27 & 0.27 \\
\hline 138 & 0.09 & 0.11 & 0.13 & 169 & 0.17 & 0.21 & 0.22 \\
\hline 139 & 0.15 & 0.12 & 0.10 & 170 & 0.22 & 0.18 & 0.19 \\
\hline 140 & 0.23 & 0.21 & 0.23 & 171 & 0.35 & 0.30 & 0.32 \\
\hline 141 & 0.28 & 0.23 & 0.26 & 172 & 0.14 & 0.14 & 0.15 \\
\hline 142 & 0.19 & 0.17 & 0.19 & 173 & 0.21 & 0.17 & 0.18 \\
\hline 143 & 0.13 & 0.15 & 0.15 & 174 & 0.22 & 0.19 & 0.20 \\
\hline 144 & 0.23 & 0.24 & 0.22 & 175 & 0.17 & 0.16 & 0.18 \\
\hline 145 & 0.24 & 0.22 & 0.23 & 176 & 0.15 & 0.19 & 0.17 \\
\hline 146 & 0.15 & 0.18 & 0.21 & 177 & 0.16 & 0.24 & 0.21 \\
\hline 147 & 0.17 & 0.18 & 0.20 & 178 & 0.16 & 0.20 & 0.20 \\
\hline 148 & 0.24 & 0.25 & 0.24 & 179 & 0.25 & 0.25 & 0.25 \\
\hline 149 & 0.14 & 0.22 & 0.19 & 180 & 0.23 & 0.21 & 0.22 \\
\hline 150 & 0.17 & 0.23 & 0.21 & 181 & 0.18 & 0.20 & 0.19 \\
\hline 151 & 0.28 & 0.25 & 0.23 & 182 & 0.36 & 0.30 & 0.34 \\
\hline 152 & 0.27 & 0.16 & 0.18 & 183 & 0.14 & 0.16 & 0.14 \\
\hline 153 & 0.33 & 0.3 & 0.28 & 184 & 0.16 & 0.12 & 0.12 \\
\hline 154 & 0.18 & 0.24 & 0.27 & 185 & 0.19 & 0.24 & 0.24 \\
\hline \multirow[t]{2}{*}{155} & 0.22 & 0.24 & 0.21 & 186 & 0.13 & 0.15 & 0.16 \\
\hline & & & & Average & $0.21 \pm 0.07$ & $0.20 \pm 0.06$ & $0.21 \pm 0.06$ \\
\hline
\end{tabular}




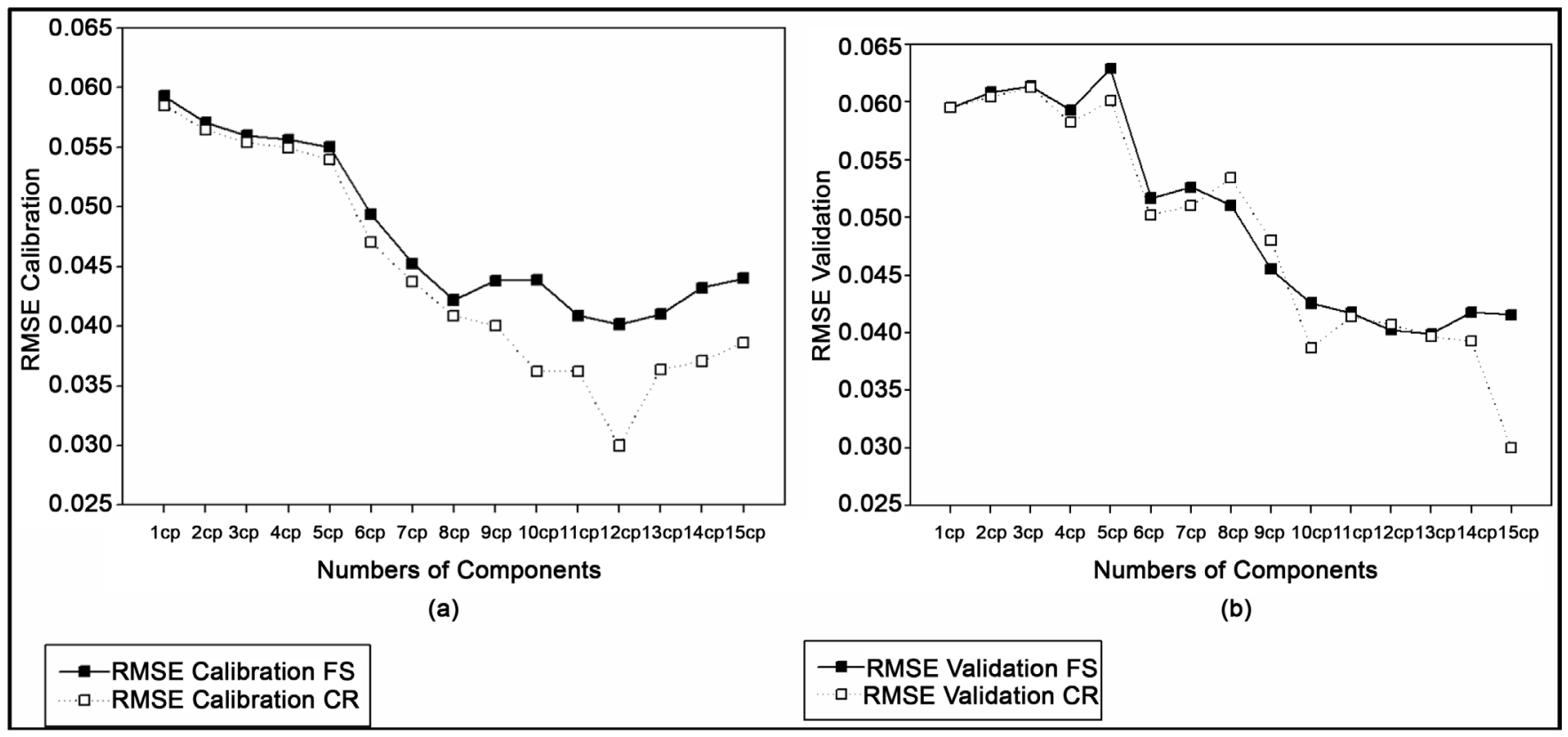

Figure 7. Effect of continuum removal in the RMSE SOC prediction.

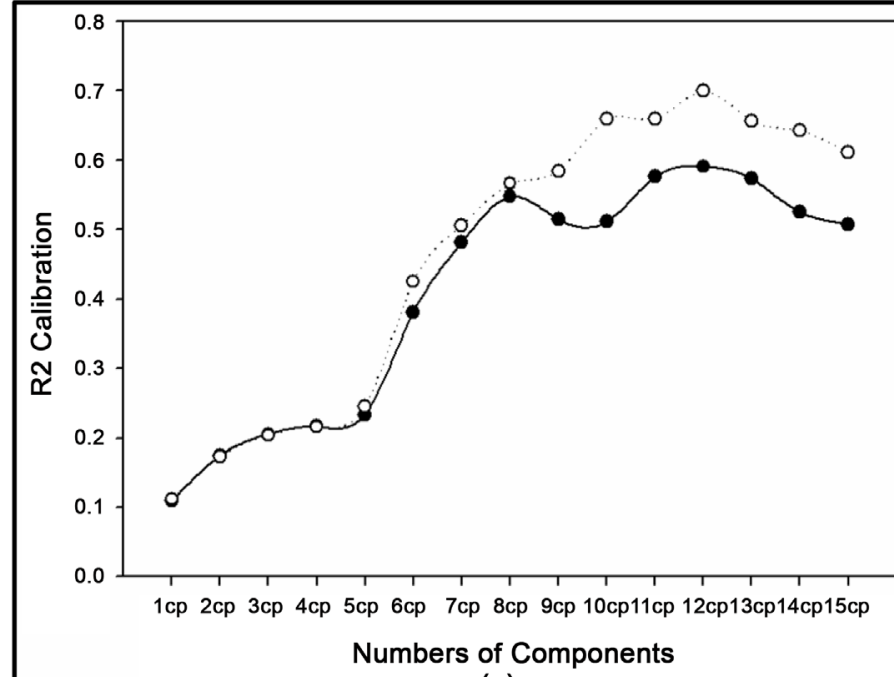

(a)

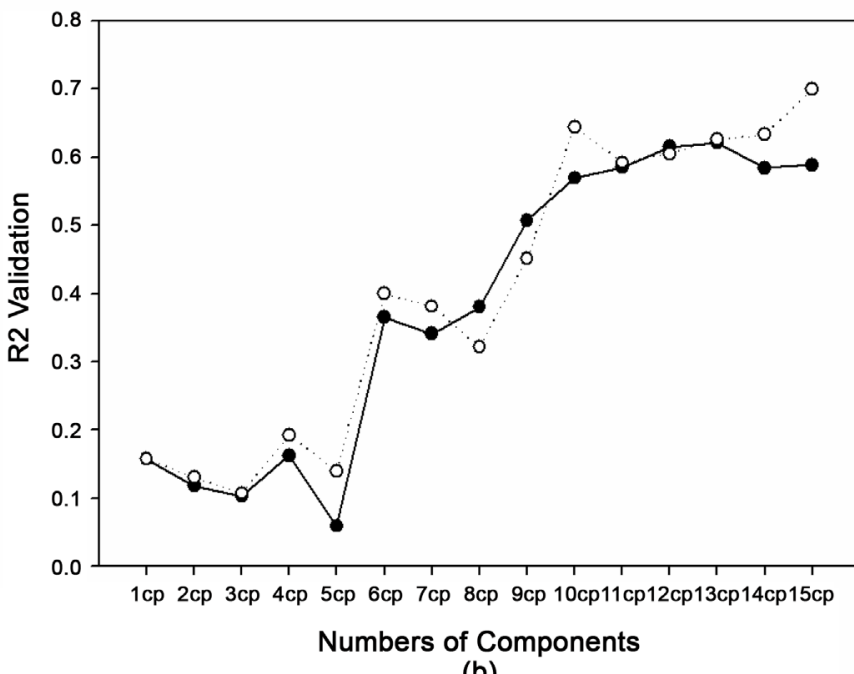

(b)

\section{$\rightarrow-$ R2 Calibration FS \\ o... R2 Calibration CR}

\section{$\rightarrow-$ R2 Validation FS \\ - ....R2 Validation CR}

Figure 8. Effect of continuum removal in the R2 SOC prediction.

\section{Discussion}

Continuum Removal (CR) has allowed improving the estimation of soil organic carbon by spectroscopy with the PLSR model. In calibration, organic carbon is predicted with a coefficient of determination ranging from 60\% (RMSE; 0.04) in the full spectrum (SP) to $70 \%$ (RMSE; 0.03 ) with the application of the CR. These result showed that the organic matter content can have a linear or curvilinear relationship with reflectance in the 
visible and infrared range [27]. The reflectance values of these spectral regions are taken into account in the estimation of the soil organic carbon. Like others results [23] [28], this study emphasized the interest to implement the preprocessing methods on the spectral libraries data achieving with Vis-NIR spectroscopy before predicting physical and chemical soil properties. The application of CR in the estimation of biochemical and chemical properties of soil highlighted a particular interest in the extent to organic carbon was recognized as a soil quality indicator in Sahelian farming systems [4] [28][36]. So, in the challenge for the quantification of the spatio-temporal dynamics of carbon storage at the plot, landscape and national scales [37], the potential of contribution of Vis-NIR technology is very important. This quantification requires high spatial densities of soil samples [5] and Vis-NIR spectroscopy offer possibilities to analyse physical and chemical soil properties with a lower coast and less time by using accurate model of prediction.

\section{Conclusion}

This study has allowed on the one hand to understand better the application modalities of the continuum removal method in the spectroscopy of soil samples. Indeed, when the value of the continuum removal (CR) equals to 1 , the full spectrum (FS) and the continuum curve (CC) will present the same values of reflectance. On the other hand, our result ( $R 2$ equals to 0.7 and $R M S E \leq 0.03$ ) obtained with the application of $\mathrm{CR}$ is acceptable. However other method of pre-processing data like the multiplicative scatter correction function [23] must be tested for improving the accuracy of the prediction model of soil organic carbon with Vis-NIR spectroscopy. It's also necessary to perform the neural network model on this dataset in order to better evaluate the effect of the continuum removal in the estimation of physical and chemical soil properties. This approach is a mean to better evaluate the performance of different data mining models for the study of the soil properties related to the Vis-NIR spectroscopy data.

\section{References}

[1] Gomez, C., Lagacherie, P. and Couloum, G. (2008) Continuum Removal versus PLSR Method for Clay and Calcium Carbonate Content Estimation from Laboratory and Airborne Hyperspectral Measurements. Geoderma, 148, 141-148.

[2] Viscarra Rossel, R.A., Walvoort, D.J.J., McBratney, A.B., Janik, L.J. and Skjemstad, J.O. (2006) Visible, Near Infrared, Mid Infrared or Combined Diffuse Reflectance Spectroscopy for Simultaneous Assessment of Various Soil Properties. Geoderma, 131, 59-75. http://dx.doi.org/10.1016/j.geoderma.2005.03.007

[3] Dunn, B.W., Beecher, H.G., Batten, G.D. and Ciavarella, S. (2002) The Potential of Near-Infrared Reflectance Spectroscopy for Soil Analysis-A Case Study from the Reiverine Plain of South-Eastern Australia. Australian Journal of Experimental Agriculture, 42, 607 614. http://dx.doi.org/10.1071/EA01172

[4] Diack, M. and Loum, M. (2014) Caractérisation par approche géostatistique de la variabilité des propriétés du sol de la ferme agropastorale de l'Université Gaston Berger (UGB) de Saint-Louis, dans le Bas delta du fleuve Sénégal. Revue Leidi, 12, 1-15.

[5] Janik, L.J., Forrester, S.T. and Rawson, A. (2009) The Prediction of Soil Chemical and 
Physical Properties from Mid-Infrared Spectroscopy and Combined Partial Least-Squares Regression and Neural Networks (PLS-NN) Analysis. Chemometrics and Intelligent Laboratory Systems, 97, 179-188.

[6] Feller, C. (1995) La matière organique du sol: Un indicateur de la fertilité. Application aux zones sahélienne et soudanienne. Agriculture \& Développement, 8, 35-41.

[7] Pieri, C. (1989) Fertilité des terres : bilan de trente ans de recherche et de développement agricole au sud du Sahara. Ministère de la coopération française, CIRAD-IRAT, 444 p.

[8] FAO (2009) Le défi spécifique à l'Afrique subsaharienne. Comment nourrir le monde en 2050. Forum d'Experts de Haut Niveau Rome, 4 p.

[9] FAO (2004) Carbon Sequestration in Dryland Soils. Rome, 109 p.

[10] Brown, D.J., Shepherd, K.D., Walsh, M.G., Maysc, D.M. and Reinsch, T.G. (2006) Global Soil Characterization with VNIR Diffuse Reflectance Spectroscopy. Geoderma, 132, 273290. http://dx.doi.org/10.1016/j.geoderma.2005.04.025

[11] Chang, C.W., Laird, D.A., Mausbach, M.J. and Hurburgh, C.R. (2001) Near-Infrared Reflectance Spectroscopy-Principal Components Regression Analyses of Soil Properties Soil Science. Society American Journal, 65, 480-490.

[12] Islam, K., Singh, B. and McBratney, A. (2003) Simultaneous Estimation of Several Soil Properties by Ultra-Violet, Visible and Near Infrared Reflectance Spectroscopy. Australian Journal of Soil Research, 41, 1101-1114.

[13] Mouazen, A.M., Kuang, B., Baerdemaeker, J.D. and Ramon, H. (2010) Comparison among Principal Component Partial Least Squares and Back Propagation Neural Network Analyses for Accuracy of Measurement of Selected Soil Properties with Visible and Near Infrared Spectroscopy. Geoderma, 158, 23-31.

[14] Viscarra Rossel, R.A. and Behrens, T. (2010) Using Data Mining to Model and Interpret Soil Diffuse Reflectance Spectra. Geoderma, 158, 46-54.

[15] Zornoza, R., Guerrero, C., Mataix-Solera, J., Scow, K.M., Arcenegui, V. and MataixBeneyto, J. (2008) Near Infrared Spectroscopy for Determination of Various Physical, Chemical and Biochemical Properties in Mediterranean Soils. Soil Biology \& Biochemistry, 40, 1923-1930. http://dx.doi.org/10.1016/j.soilbio.2008.04.003

[16] Nocita, M., Stevens, A., Wesemael, B., van Aitkenhead, M., Bachmann, M., Barthes, B., Ben Dor, E., Brown, D.J., Clairotte, M., Csorba, A., Dardenne, P., Demattê, J.A.M., Genoty, V., Guerrero, C., Knadel, M., Montanarella, L., Noonx, C., Ramirez-Lopez, L., Robertson, J., Sakai, H., Soriano-Disla, J.M., Shepherd, K.D., Stenberg, B.,Towett, E.K., Vargas R. and Wetterlind, J. (2015) Soil Spectroscopy: An Alternative to Wet Chemistry for Soil Monitoring. Advances in Agronomy, 132, 139-159.

http://dx.doi.org/10.1016/bs.agron.2015.02.002

[17] Viscarra, R.A, Cattle, S.R., Ortega, A. and Fouad, Y. (2009) In Situ Measurements of Soil Colour, Mineral Composition and Clay Content by Vis-NIR Spectroscopy. Geoderma, 150, 253-266. http://dx.doi.org/10.1016/j.geoderma.2009.01.025

[18] McCarty, G.W., Reeves, J.B., Reeves, V.B., Follett, R.F. and Kimble, J.M. (2002) Mid- Infrared and Near-Infrared Diffuse Reflectance Spectroscopy for Soil Carbon Measurement. Soil Science Society American Journal, 66, 640-646.

[19] Viscarra Rossel, R.A., McGlynn, R.N. and McBratney, A.B. (2006) Determining the Composition of Mineral-Organic Mixes Using UV-vis-NIR Diffuse Reflectance Spectros- copy. Geoderma, 137, 70-82. http://dx.doi.org/10.1016/j.geoderma.2006.07.004

[20] Clark, R.N. and Roush, L. (1984) Reflectance Spectroscopy Quantitative Analysis Techniques for Remote Sensing Applications. Journal of Geophysical Research, 89, 6329-6340. http://dx.doi.org/10.1029/JB089iB07p06329 
[21] Noomen, M.F., Skidmore, A.K., Van der Meer, F.D. and Herbert, H.H.T. (2006) Continuum Removed Band Depth Analysis for Detecting the Effects of Natural Gas, Methane and Ethane on Maize Reflectance. Remote sensing of Environment, 105, 262-270.

http://dx.doi.org/10.1016/j.rse.2006.07.009

[22] Zimmermann, M., Leifeld, J. and Fuhrer, J. (2007) Quantifying Soil Organic Carbon Fractions by Infrared-Spectroscopy. Soil Biology \& Biochemistry, 39, 224-231.

http://dx.doi.org/10.1016/j.soilbio.2006.07.010

[23] Feyziyev, F., Babayev, M., Priori, S. and L’Abate, G. (2016) Using Visible-Near Infrared Spectroscopy to Predict Soil Properties of Mugan Plain, Azerbaijan. Open Journal of Soil Science, 6, 52-58. http://dx.doi.org/10.4236/ojss.2016.63006

[24] Tenenhaus, M. (1998) La régression PLS, théorie et pratique. Editions Technip, Paris.

[25] Mevik, B.H. and Wherens, R. (2007) The Pls Package: Principal Component and Partial least Squares Regression in R. Journal of Statistical Software, 18, 1-24.

http://dx.doi.org/10.18637/jss.v018.i02

[26] Aïchi, H., Fouad, Y., Walter, C., Viscarra, R.A.R., Chabaane, Z.L. and Sanaa, M. (2009) Regional Prediction of Soil Carbon Content from Spectral Reflectance Measurements. Biosystems Engineering, 104, 442-446.

http://dx.doi.org/10.1016/j.biosystemseng.2009.08.002

[27] Chen, F., Kissel, D.E., West, L.T., Adkins, W. and Luvall, D.R. (2008) Mapping Soil Organic Carbon Concentration for Multiple Fields with Image Similarity Analysis. Soil Science Society American Journal, 72, 186-193. http://dx.doi.org/10.2136/sssaj2007.0028

[28] Manlay, R.J., Feller, C. and Swift, M.J. (2007) Historical Evolution of Soil Organic Matter Concepts and Their Relationships with the Fertility and Sustainability of Cropping Systems. Agriculture, Ecosystems and Environment, 119, 217-233.

http://dx.doi.org/10.1016/j.agee.2006.07.011

[29] Elberling, B., Touré, A. and Rasmussen, K. (2003) Changes in Soil Organic Matter Following Groundnut-Millet Cropping at Three Locations in Semi-Arid Senegal, West Africa. Agriculture, Ecosystems and Environment, 96, 37-47. http://dx.doi.org/10.1016/S0167-8809(03)00010-0

[30] Loum, M., Viaud, V., Fouad, Y., Nicolas, H. and Walter, C. (2014) Retrospective and Prospective Dynamics of Soil Carbon Sequestration in Sahelian agrosystems in Senegal. Journal of Arid Environments, 100-101, 100-105. http://dx.doi.org/10.1016/j.jaridenv.2013.10.007

[31] Lufafa, A., Diédhiou, I., Samba, S.A.N., Séne, M., Khouma, M., Kizito, F., Dick, R.P., Dossa, E. and Noller, J.S. (2008) Carbon Stocks and Patterns Native Shrub Communities of Senegal's Peanut Basin. Geoderma, 146, 75-82. http://dx.doi.org/10.1016/i.geoderma.2008.05.024

[32] Manlay, R.J., Feller, C. and Swift, M.J. (2007) Historical Evolution of Soil Organic Matter Concepts and Their Relationships with the Fertility and Sustainability of Cropping Systems. Agriculture, Ecosystems and Environment, 119, 217-233. http://dx.doi.org/10.1016/j.agee.2006.07.011

[33] Masse, D. (2007) Changements d'usage des terres dans les agrosystèmes d'Afrique subsaharienne. Propriétés des sols et dynamique des matières organiques. HDR, Ecole Nationale Supérieure Agronomique de Toulouse, , France, 82 p.

[34] Ndour, N.Y.B., Fardoux, J. and Chotte, J.L. (2000) Statut Organique et microbiologique de sols ferrugineux tropicaux en jachère naturelle. In: Pontanier, R. and Floret, C., Eds., La jachère en Afrique tropicale, IRD, John Libbey Eurotext, Paris, 354-360. 
[35] Toure, A., Temgoua E., Guenat C. and Elberling, B. (2013) Land Use and Soil Texture Effects on Organic Carbon Change in Dryland Soils, Senegal. Open Journal of Soil Science, 3, 253-262. http://dx.doi.org/10.4236/ojss.2013.36030

[36] Tschakert, P., Khouma, M. and Sene, M. (2004) Biophysical Potential for Soil Carbon Sequestration in Agricultural Systems of the Old Peanut Basin of Senegal. Journal of Arid Environments, 59, 511-533. http://dx.doi.org/10.1016/j.jaridenv.2004.03.026

[37] Viaud, V., Anger, D.A. and Walter, C. (2010) Toward Landscape-Scale Modeling of Soil Organic Matter Dynamics Agroecosystems. Soil Science Society of America Journal, 74, 1847-1860. http://dx.doi.org/10.2136/sssaj2009.0412

\section{Submit or recommend next manuscript to SCIRP and we will provide best service} for you:

Accepting pre-submission inquiries through Email, Facebook, LinkedIn, Twitter, etc. A wide selection of journals (inclusive of 9 subjects, more than 200 journals)

Providing 24-hour high-quality service

User-friendly online submission system

Fair and swift peer-review system

Efficient typesetting and proofreading procedure

Display of the result of downloads and visits, as well as the number of cited articles

Maximum dissemination of your research work

Submit your manuscript at: http://papersubmission.scirp.org/

Or contactojss@scirp.org 